\title{
Corrosion Examination on Copper based Composite Under Different Environmental Conditions
}

\author{
P. Balamurugan, M. Uthayakumar, B. Anushraj
}

\begin{abstract}
Copper matrix composite reinforced with fly ash is prepared by powder metallurgy process. Three composites with $0 \%, 2.5 \%$ and $5 \%$ fly ash proportion are prepared. The specimens were compacted at $450 \mathrm{MPa}$ and Sintered at $950^{\circ} \mathrm{C}$ for a period of 30 minutes in powder metallurgy technique. The prepared specimens were subjected to different corrosion environments (alkaline and acidic) and the corroded surface will be analysed using SEM/EDX.
\end{abstract}

Keywords : Copper, Corrosion, Fly ash, Powder Metallurgy.

\section{INTRODUCTION}

Composite material is the combination of two or more materials in which one will act as matrix and the other as reinforcement. Composites with different properties can be achieved based on the matrix and reinforcement material chosen, distribution of reinforcement in the matrix interaction between the matrix and reinforcement. In the current days, metal matrix composite (MMCs) has been used around the globe, because of its superior properties in terms of strength to weight ratio, good wear and corrosion resistance compared to monolithic metals or alloys[1]. MMCs are generally produced by mixing hard or soft reinforcement phase in the metallic matrix based on the tailored requirement. Copper/copper alloys are used in wide range of applications due to its noteworthy properties such as better electrical/thermal conductivity, corrosive resistance to corrosion, non-magnetic, dimensional stability at higher temperatures etc[2]. Hard reinforcements such as $\mathrm{SiO}_{2}$ [3], $\mathrm{Al}_{2} \mathrm{O}_{3}$ [4], TiC[5], $\mathrm{SiC}$,[6] $\mathrm{B}_{4} \mathrm{C}$ [7] and $\mathrm{WC}[8]$ are added to copper matrix in order to enhance properties stability at higher temperatures \& wear resistance. Soft reinforcements such as graphite[9] and $\mathrm{MoS}_{2}$ [10] are added to the copper matrix to reduce the friction. Fly ash is the residue generated by burning coal in the furnace, which is one to the promising reinforcement used by various researchers to produce metal matrix composites due to its abundant availability at low cost and to achieve the properties like high wear resistance, improved hardness and

Revised Manuscript Received on December 05, 2019.

* Correspondence Author

P. Balamurugan*, School of Automotive and Mechanical Engineering, Kalasalingam Academy of Research and Education, Krishnankoil, India. Email: pbala.klumech@gmail.com

M. Uthayakumar, School of Automotive and Mechanical Engineering, Kalasalingam Academy of Research and Education, Krishnankoil, India. Email:uthaykumar@gmail.com

Anush Raj, School of Automotive and Mechanical Engineering,

Kalasalingam Academy of Research and Education, Krishnankoil, India. Email: anushrajb@gmail.com better tensile/compression strength[11]-[13]. To achieve composites with enhanced properties the following control parameters are studied by the researchers: volume fraction between and matrix and reinforcement, particle size[14], particle shape etc., The distribution of reinforcement in the matrix impacts the properties of the composite to the larger extent[15]. Vijaya sai etal[16] studied the wear behaviour of $\mathrm{Cu}-\mathrm{Sn}$-Flyash composite and reported that enhancement in wear resistance is achieved with the addition of the fly ash. Powder metallurgy (P/M) technique[17] is preferred over other manufacturing methods if the matrix to reinforcement proportion have high variance in density[18], [19]. Copper based composites are used in various marine applications such as propellers, pump impellers and in components of missiles and torpedoes[20] where the corrosion resistance property plays a major role. Even though some studies on copper fly ash composite is available[21], [22], the effect of addition of fly ash on corrosive behaviour of copper fly ash is not yet reported to the best of our knowledge. In the present study copper - fly ash composite with varying proportions of fly ash is prepared through $\mathrm{P} / \mathrm{M}$ technique and studies were carried to find the corrosive behaviour of the composite under acidic and alkaline environmental conditions.

\section{MATRIALS AND METHODS}

\section{A. Materials used}

Copper metal powder with $99.7 \%$ purity (Oxford Chemicals, India) is used as the matrix. The density of copper is $8940 \mathrm{~kg} / \mathrm{m}^{3}$. Fly ash obtained from Tuticorin Thermal Power Station - India, is used as the reinforcement material. Its density is $890 \mathrm{~kg} / \mathrm{m}^{3}$. The fly ash composition used for the study is as follows $\mathrm{Al}_{2} \mathrm{O}_{3}-25 \%, \mathrm{Fe}_{3} \mathrm{O} 4+\mathrm{Fe}_{2} \mathrm{O}_{3}-5 \%, \mathrm{SiO}_{2}$ $62 \%, \mathrm{MgO}-1 \%, \mathrm{CaO}-2 \%$, Unburnt carbon $4 \%$ and remaining traces.

\section{B. Preparation of the Composite}

Two Composites with proportions of 2.5 and $5 \%$ (wt.) fly ash are prepared for the study, in order to compare the influence of the addition of reinforcement, specimen without fly ash is also prepared. For the preparation of the composite the following procedure is adapted. The Matrix (Copper) and reinforcement (fly ash) in the form of powder are weighed separately at definite proportions using a Mitutoyo's digital weighing instrument of accuracy 0.1 milligrams. The powders of matrix and reinforcement after weighing at required proportions were mixed up manually. The mixture is heated to $100^{\circ} \mathrm{C}$ under inert (argon) atmosphere in order to remove if any moisture content present in the blended powders. The compaction

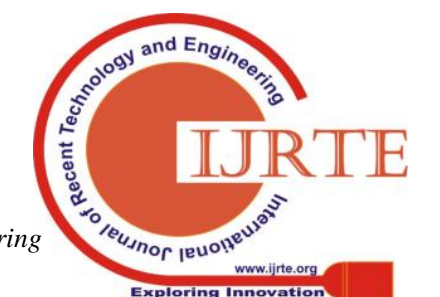


process is carried out using a die in Universal Testing Machine(UTM), in which force is given on the top of the plunger and only support is given on the bottom. To make the easier removal of specimen from the die, the die surfaces are lubricated with the wax, since the wax application lowers the adhesion of the powder with the die surfaces. The typical compaction process is presented in the Fig. 1. After the application of $450 \mathrm{MPa}$ pressure, the specimen is removed from the die, which is called as green compact

The green compact is weak since the particles only mechanically bonded. Sintering will make the bonding stronger, the specimen prepared are sintered at $950{ }^{\circ} \mathrm{C}$ using tubular furnace under argon atmosphere. The prepared specimen is having the dimensions of $\phi 20 \mathrm{~mm}$ and height $5 \mathrm{~mm}$.

\section{Corrosion Studies}

The surface to be exposed for the corrosion test is finished with the emery paper of varying grit size from 400 1500. Corrosion analysis was carried out as per standard ASTM G3-14 on 3.5(wt. \%) NaCl solution and 1M of HCL separately. During the corrosion test, the specimen is exposed to a diameter of $10 \mathrm{~mm}$ with the medium of corrosion. The parameters considered during the study are shown in the Table - I.

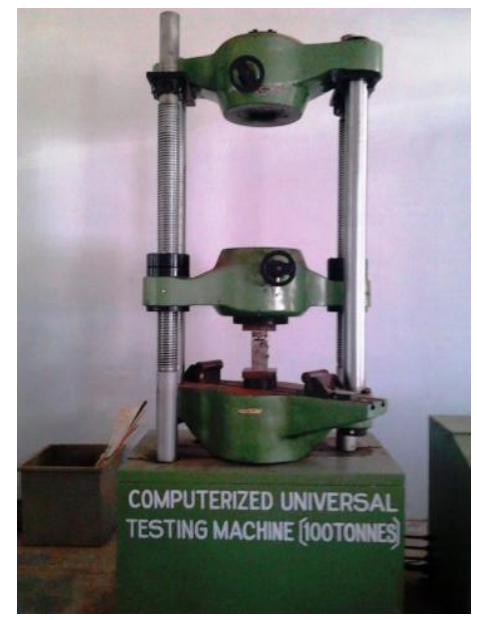

Fig. 1. Compaction using UTM

Table - I. Parameters For Corrosion Analysis

\begin{tabular}{|l|l|}
\hline Parameters & Range / Values \\
\hline Sweep rate & $10 \mathrm{mV} / \mathrm{min}$ \\
\hline $\begin{array}{l}\text { Starting and ending frequency on } \\
\text { AC impedance }\end{array}$ & $1 \mathrm{MHz}$ and $10 \mathrm{kHz}$ \\
\hline Amplitude & $10 \mathrm{mV}$ \\
\hline Potential range & $-600 \mathrm{mV}$ to $800 \mathrm{mV}$ \\
\hline
\end{tabular}

\section{RESULTS AND DISCUSSION}

To simulate the corrosive environment similar to sea water, solution with $3.5 \mathrm{wt} \% \mathrm{NaCl}$ is prepared to carry out the corrosion studies. During investigation on potentiodynamic polarization studies volt-amp graph (Tafel plot) was plotted with a rest potential refereeing to standard calomel electrode. The corrosion test results of the copper and prepared composites such as corrosion potential (Ecorr), Current Density (Icorr) and corrosion rate are shown in the Table 2. Fig. 2 and Fig. 3 shows the TAFEL plots of the copper fly ash composite and pure copper exposed to $3.5 \mathrm{wt} \% \mathrm{NaCl}$ solution and $1 \mathrm{~N}$ of HCL respectively
From the Table - II, it is inferred that as the fly ash content on the composite increases the corrosion rate decreases, which is due to the resistance to formation of corrosive product. Since fly ash is an inert material and having high chemical stability as the content of fly ash increases, the corrosion rate decreases.

The corrosion test results of copper and copper fly ash composites tested under $1 \mathrm{~N}$ of HCL solution is shown in the Table - III. The results indicate that as the fly ash content increases the corrosion rate decreases, this might be due to decrease in $\mathrm{I}_{\text {corr }}$ value as with increase fly ash content as the same time the rest potential shows the consistent improvement in positive direction from 140.56 to $-52.62 \mathrm{mv}$ with the addition of fly ash of $5 \%$.

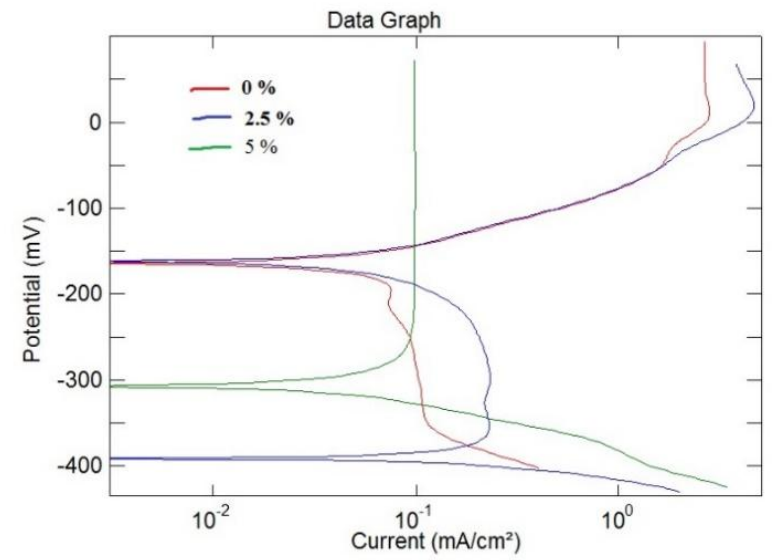

Fig. 2. TAFEL plot of materials tested under $\mathrm{NaCl}$ solution

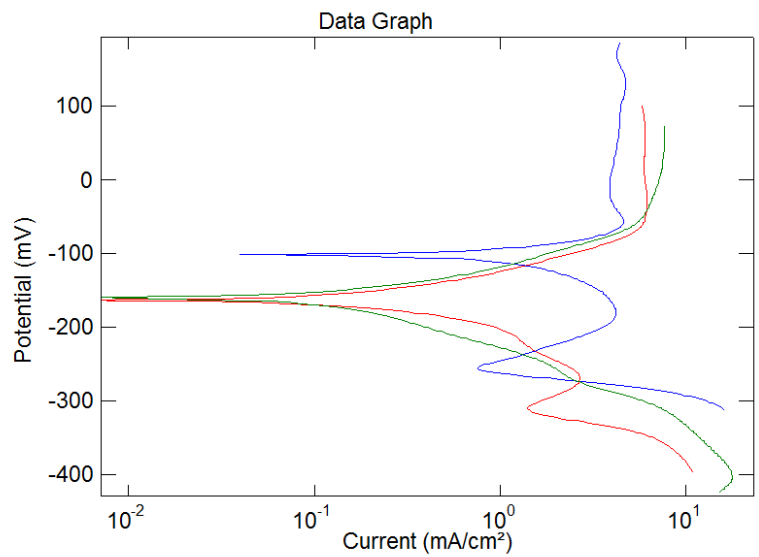

Fig. 3. TAFEL plot of materials tested under HCL solution

Table - II. Corrosion test results under $\mathrm{NaCl}$ solution

\begin{tabular}{|c|c|c|c|c|}
\hline $\begin{array}{c}\text { Materia } \\
\mathbf{I}\end{array}$ & $\begin{array}{c}\text { Rest } \\
\text { potential } \\
(\mathbf{m v})\end{array}$ & $\begin{array}{c}\text { I-corr } \\
\left(\mathbf{m A} / \mathbf{c m}^{2}\right)\end{array}$ & $\begin{array}{c}\mathbf{E}-\mathbf{c o r r} \\
(\mathbf{m V})\end{array}$ & $\begin{array}{c}\text { Corrosion } \\
\text { rate } \\
\mathbf{m m} / \mathbf{y e a r}\end{array}$ \\
\hline $0 \%$ & -162.78 & 0.3950 & -179.80 & 9.1883 \\
\hline $2.5 \%$ & -122.18 & 0.2797 & -152.72 & 6.5078 \\
\hline $5 \%$ & -172.75 & 0.0627 & -175.06 & 1.4591 \\
\hline
\end{tabular}

Table - III. Corrosion test results under 1m of HCL solution

\begin{tabular}{|c|c|c|c|c|}
\hline $\begin{array}{c}\text { Materia } \\
\mathbf{l}\end{array}$ & $\begin{array}{c}\text { Rest } \\
\text { potential } \\
\mathbf{m v}\end{array}$ & $\begin{array}{c}\text { I-corr } \\
\left(\mathbf{m A} / \mathbf{c m}^{2}\right)\end{array}$ & $\begin{array}{l}\text { E-corr } \\
(\mathbf{m V})\end{array}$ & $\begin{array}{c}\text { Corrosion } \\
\text { rate } \\
(\mathbf{m m} / \mathbf{y e a r})\end{array}$ \\
\hline $0 \%$ & -140.56 & 0.3827799 & -161.28 & 8.9034 \\
\hline $2.5 \%$ & -111.68 & 0.3019565 & -168.46 & 6.8044 \\
\hline $5 \%$ & -52.62 & 0.2925388 & -256.25 & 2.9589 \\
\hline
\end{tabular}



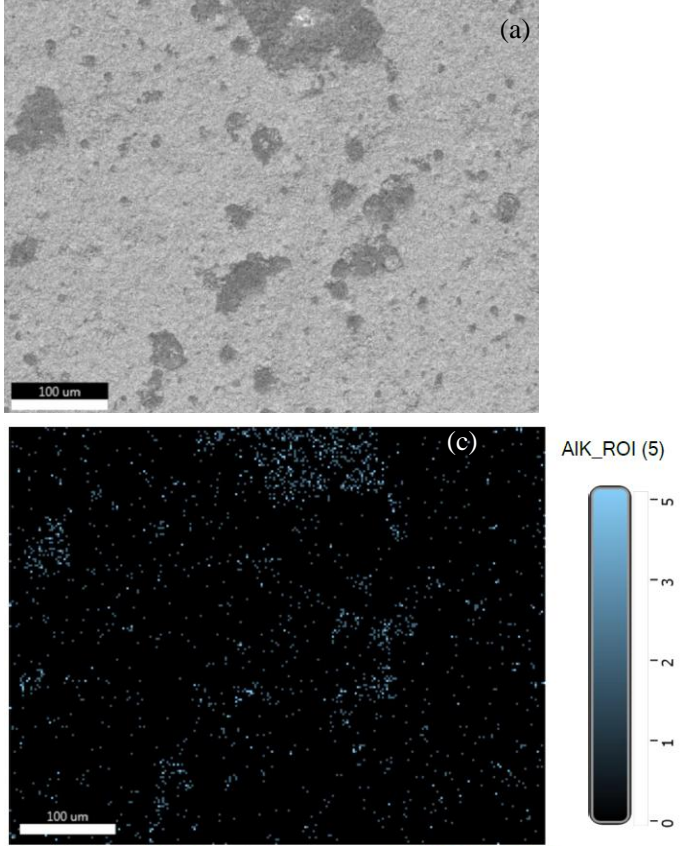

(e)

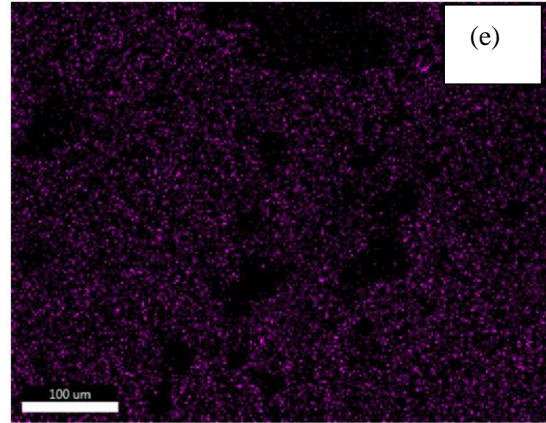

CIK_ROI (9)

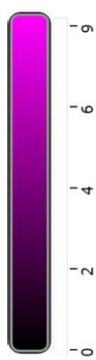

Fig. 4. EDS mapping of various elements in Copper fly ash composite after corrosion test under HCL solution: (a) SEM Image, (b)O, (c) Al, (d)Si, (e)Cl \& (f)Cu

\section{CONCLUSION}

- Copper flyash composite was successfully fabricated using powder metallurgy techniques.

- Addition of flyash as reinforcement increases the corrosion resistance because of the reduction in chloride formation.

- Composites are tested under alkaline medium exhibits less corrosion than acidic medium.

\section{REFERENCES}

1. B. N. Chawla and Y. Shen, "Mechanical Behavior of Particle Reinforced Metal Matrix Composites **," no. 6, pp. 357-370, 2001

2. S. -b. Kang, "Thermal conducting property of SiCp-reinforced copper matrix composites by hot pressing," J. Compos. Mater., vol. 45, no. 18, pp. $1849-1852$, Dec. 2010

3. S. C. P. Thermadam, S. K. Bhagat, T. L. Alford, Y. Sakaguchi, and M. N Kozicki, "Influence of $\mathrm{Cu}$ Diffusion Conditions on the Switching of Cu-SiO2-Based Resistive Memory Devices," 2009.

4. V. Rajkovic, D. Bozic, and M. T. Jovanovic, "Properties of copper matrix reinforced with various size and amount of Al2O3 particles," J. Mater Process. Technol., vol. 200, no. 1-3, pp. 106-114, May 2008.

5. K. Rajkumar and S. Aravindan, "Tribological performance of microwave sintered copper - TiC - graphite hybrid composites," Tribol. Int., vol. 44, no. 4, pp. 347-358, 2011.

6. S. Kayal, R. Behera, and G. Sutradhar, "Mechanical properties of the as-cast silicon carbide particulate reinforced Aluminium alloy Metal Matrix Composites," vol. 2, no. 3, pp. 318-322, 2012.

7. S. T. Kumaran and M. Uthayakumar, "Investigation of the dry sliding friction and wear behavior of AA6351-SiC-B4C hybrid metal matrix composites," Proc. Inst. Mech. Eng. , Part J J. Eng. Tribol., p. DOI: $10.1177 / 1350650113508103,2013$
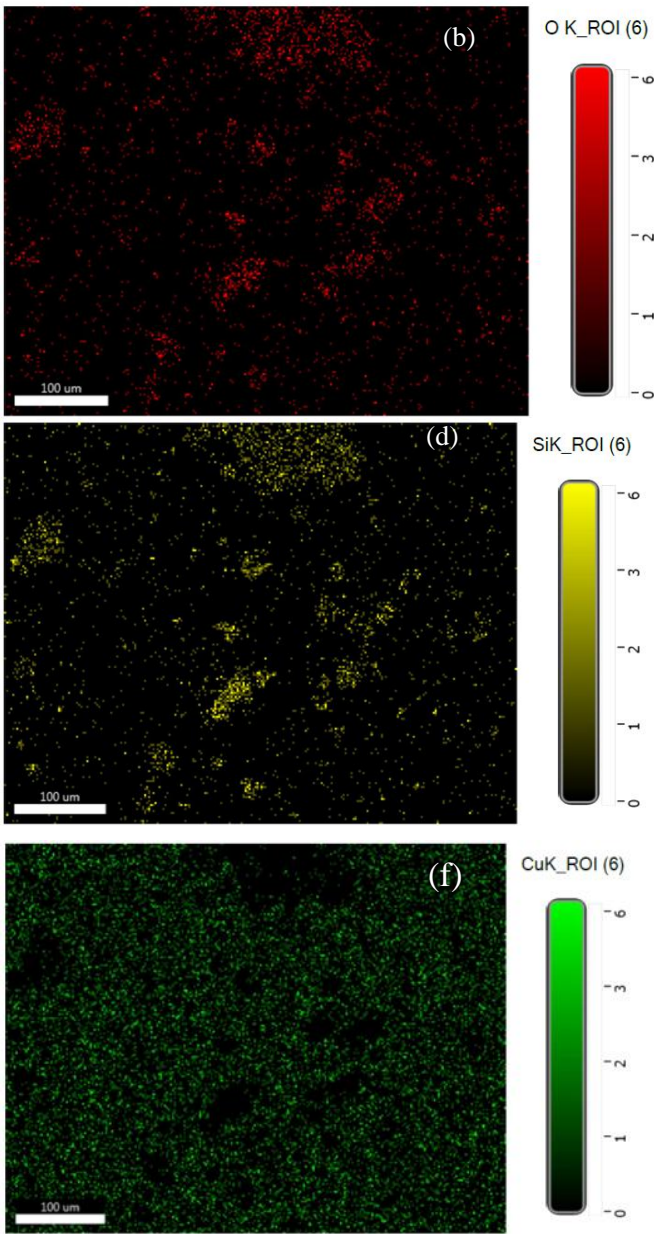

CuK_ROI (6)

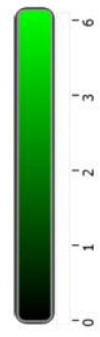

8. Y. Zhang, Y. Epshteyn, and R. R. Chromik, "Dry sliding wear behaviour of cold-sprayed $\mathrm{Cu}-\mathrm{MoS} 2$ and $\mathrm{Cu}-\mathrm{MoS} 2-\mathrm{WC}$ composite coatings: The influence of WC," Tribol. Int., vol. 123, pp. 296-306, 2018.

9. C. P. Samal, J. S. Parihar, and D. Chaira, "The effect of milling and sintering techniques on mechanical properties of $\mathrm{Cu}$-graphite meta matrix composite prepared by powder metallurgy route," J. Alloys Compd., vol. 569, pp. 95-101, Aug. 2013.

10. A. M. Kovalchenko, O. I. Fushchich, and S. Danyluk, "The tribologica properties and mechanism of wear of $\mathrm{Cu}$-based sintered powder materials containing molybdenum disulfide and molybdenum diselenite under unlubricated sliding against copper," Wear, vol. 290-291, pp. 106-123, Jun. 2012.

11. P. NARAYANASAMY and N. SELVAKUMAR, "Tensile, compressive and wear behaviour of self-lubricating sintered magnesium based composites," Trans. Nonferrous Met. Soc. China, vol. 27, no. 2, pp. 312-323, 2017

12. H. S. Lee, J. S. Yeo, S. H. Hong, D. J. Yoon, and K. H. Na, "The fabrication process and mechanical properties of $\mathrm{SiC} \mathrm{p} / \mathrm{Al} \pm \mathrm{Si}$ metal matrix composites for automobile air-conditioner compressor pistons,' vol. 113, pp. 202-208, 2001.

13. P. Gupta, D. Kumar, O. M. Parkash, and A. K. Jha, "Structural and mechanical behaviour of $5 \% \mathrm{Al} 2 \mathrm{O} 3$-reinforced Fe metal matrix composites ( MMCs ) produced by powder metallurgy ( P / M ) route,' vol. 36, no. 5, pp. 859-868, 2013.

14. G. C. Efe, I. Altinsoy, M. Ipek, S. Zeytin, and C. Bindal, "Effects of SiC Particle Size on Properties of $\mathrm{Cu}-\mathrm{SiC}$ Metal Matrix Composites," ACTA Phys. Pol. A, vol. 121, no. 1, pp. 251-253, 2012.

15. M. K. Apalak, R. Ekici, M. Yildirim, and F. Nair, "Effects of Random Particle Dispersion and Particle Volume Fraction on the Indentation Behavior of SiC Particle-Reinforced Metal-Matrix Composites," J. Compos. Mater., vol. 43, no. 26, pp. 3191-3210, Sep. 2009.

16. N. V. Sai, M. Komaraiah, and A. V. S. R. Raju, "Preparation and Properties of Sintered Copper-Tin Composites Containing Copper Coated or 
Uncoated Fly Ash,” Mater. Manuf. Process., vol. 23, no. 7, pp. 651-657, Sep. 2008.

17. T. Senthilvelan, K. Raghukandan, and a Venkatraman, "Modelling of process parameters on the working of $\mathrm{P} / \mathrm{M}$ copper preforms," J. Mater. Process. Technol., vol. 142, no. 3, pp. 767-772, Dec. 2003.

18. A. Mukhtar, D. L. Zhang, C. Kong, and P. Munroe, "Variation in Hardness of Untrafine Grained Cu - Al2O3 Composite Hollow Balls and Granules Produced by High Energy Mechanical Milling," Mater. FORUM, vol. 32, pp. 2-6, 2008.

19. C. A. Vogiatzis, A. Tsouknidas, D. T. Kountouras, and S. Skolianos, "Aluminum-ceramic cenospheres syntactic foams produced by powder metallurgy route," Mater. Des., vol. 85, no. 1, pp. 444-454, 2015.

20. J. E. Orth and H. G. Wheat, "Corrosion behavior of high energy-high rate consolidated graphite/copper metal matrix composites in chloride media," Appl. Compos. Mater., vol. 4, no. 5, pp. 305-320, 1997.

21. P. Balamurugan and M. Uthayakumar, "Influence of Process Parameters on Cu-Fly Ash Composite by Powder Metallurgy Technique," Mater. Manuf. Process., vol. 30, no. 3, pp. 313-319, 2015.

22. P. Balamurugan and M. Uthayakumar, "Wear Studies on SiC and Fly Ash Reinforced Copper Based Composites by Grey Relational Analysis," Adv. Mater. Res., vol. 984-985, pp. 304-312, 2014.

\section{AUTHORS PROFILE}

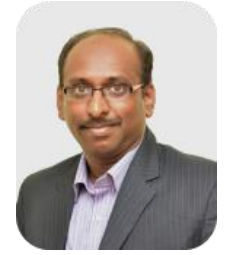

Dr. P. Balamurugan has obtained his Doctoral Degree from Kalasalingam University, India. He is doing research in the area of Characterization, Mechanical, Tribological, Corrosion and erosion studies of metal matrix composites. Currently he is working as Associate Professor in Department of Mechanical Engineering, Kalasalingam Academy of Research and Education, India.

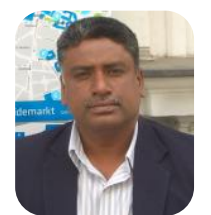

Dr. M. Uthayakumar has obtained Master of Engineering in Production Engineering from Thiagarajar College of Engineering (Autonomous), Madurai, India and Doctorate from Department of Production Engineering, National Institute of Technology, Tiruchirappalli. He has published 145 papers in the international journals and conference. Currently he is a Professor at Department of Mechanical Engineering, Kalasalingam Academy of Research and Education, Krishnankoil, Virudhunagar Dist.

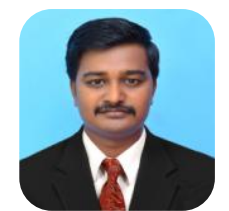

Mr. Anushraj B graduated in 2012 from St.Xavier's Catholic College of Engineering, India. In 2014, he received his M.E Degree in Energy Engineering from Regional Campus of Anna University, Tirunelveli, India. Currently, he is a research scholar at Kalasalingam Academy of Research and Education, India. 